\title{
A Taxonomy for Mechanical Ventilation: 10 Fundamental Maxims
}

\author{
Robert L Chatburn MHHS RRT-NPS FAARC, Mohamad El-Khatib PhD MD RRT FAARC, \\ and Eduardo Mireles-Cabodevila MD
}

\author{
Introduction \\ What Is a Mode of Mechanical Ventilation? \\ The 10 Maxims \\ Application of the Taxonomy \\ Discussion \\ The Problem of Growing Complexity \\ The Problem of Identifying Unique Modes \\ The Problem of Teaching Mechanical Ventilation \\ The Problem of Implementation \\ Conclusions
}

\begin{abstract}
The American Association for Respiratory Care has declared a benchmark for competency in mechanical ventilation that includes the ability to "apply to practice all ventilation modes currently available on all invasive and noninvasive mechanical ventilators." This level of competency presupposes the ability to identify, classify, compare, and contrast all modes of ventilation. Unfortunately, current educational paradigms do not supply the tools to achieve such goals. To fill this gap, we expand and refine a previously described taxonomy for classifying modes of ventilation and explain how it can be understood in terms of $\mathbf{1 0}$ fundamental constructs of ventilator technology: (1) defining a breath, (2) defining an assisted breath, (3) specifying the means of assisting breaths based on control variables specified by the equation of motion, (4) classifying breaths in terms of how inspiration is started and stopped, (5) identifying ventilator-initiated versus patient-initiated start and stop events, (6) defining spontaneous and mandatory breaths, (7) defining breath sequences (8), combining control variables and breath sequences into ventilatory patterns, (9) describing targeting schemes, and (10) constructing a formal taxonomy for modes of ventilation composed of control variable, breath sequence, and targeting schemes. Having established the theoretical basis of the taxonomy, we demonstrate a step-by-step procedure to classify any mode on any mechanical ventilator. Key words: taxonomy; ontology; mechanical ventilation; mechanical ventilator; modes of ventilation; classification; ventilator; survey; standardized nomenclature; controlled vocabulary. [Respir Care 2014;59(11):1747-1763. (C) 2014 Daedalus Enterprises]
\end{abstract}

\section{Introduction}

The American Association for Respiratory Care (AARC) has sponsored a number of conferences to outline the com-

Mr Chatburn and Dr Mireles-Cabodevila are affiliated with the Respiratory Institute, Cleveland Clinic, Cleveland, Ohio and the Lerner College of Medicine of Case Western Reserve University, Cleveland, Ohio. petencies of the registered respiratory therapist (RRT) of the future. ${ }^{1-3}$ One of the competencies in the area of critical care was declared as the ability to "apply to practice

\footnotetext{
Dr El-Khatib is affiliated with the Department of Anesthesiology, American University of Beirut Medical Center, Beirut, Lebanon.

Supplementary material related to this paper is available at http:// www.rcjournal.com.
} 
all ventilation modes currently available on all invasive and noninvasive mechanical ventilators, as well as all adjuncts to the operation of modes." ${ }^{2} \mathrm{Kacmarek}^{4}$ recently published a paper discussing the expectations of this future RRT regarding mechanical ventilation competencies. (Of course, these competencies apply to any clinician responsible for managing ventilated patients, as many countries do not have RRTs.) He states that:

The RT of 2015 and beyond must be a technical expert on every aspect of the mechanical ventilator. They should be able to discuss all of the technical nuances of the mechanical ventilator. They should be able to compare the capabilities of one ventilator to the other. They should be able to discuss in detail the mechanism of action of all of the modes and adjuncts that exist on the mechanical ventilator.

He further says that "The RT of 2015 and beyond should be capable of defining the operational differences between each of these modes." These statements seem reasonable at first glance, but further consideration reveals some major challenges.

The number of modes of ventilation has grown exponentially in the last 3 decades. Consider just one popular textbook on respiratory care equipment ${ }^{5}$ that includes 174 unique names of modes on 34 different ventilators. The level of complexity in terms of the real number of unique modes is much greater: most ICU ventilators allow the operator to activate various features that modify a given mode and actually transform it into anther mode without any naming convention to signify the transition. The result is that there are many more unique modes (in terms of different patterns of patient-ventilator interaction) than there are names indicated on the ventilators, in operators' manuals, or in textbooks. This growing complexity has generated an urgent need for a classification system (taxonomy) for modes of mechanical ventilation to facilitate the identification and comparison of the technical capabilities of ventilators.

The purpose of this article is to describe a formal taxonomy for modes of mechanical ventilation (ie, a classification of modes into groups based on similar character-

Mr Chatburn is a paid consultant for Philips Respironics, Covidien, Dräger, Hamilton Medical, and ResMed. The other authors have disclosed no conflicts of interest.

Correspondence: Robert L Chatburn MHHS RRT-NPS FAARC, Cleveland Clinic, M-56, 9500 Euclid Avenue, Cleveland, OH 44195. E-mail: chatbur@ccf.org.

DOI: $10.4187 /$ respcare. 03057
Table 1. Ten Basic Maxims for Understanding Ventilator Operation

(1) A breath is one cycle of positive flow (inspiration) and negative flow (expiration) defined in terms of the flow vs time curve.

(2) A breath is assisted if the ventilator provides some or all of the work of breathing.

(3) A ventilator assists breathing using either pressure control or volume control based on the equation of motion for the respiratory system.

(4) Breaths are classified according to the criteria that trigger (start) and cycle (stop) inspiration.

(5) Trigger and cycle events can be either patient-initiated or ventilator-initiated.

(6) Breaths are classified as spontaneous or mandatory based on both the trigger and cycle events.

(7) Ventilators deliver 3 basic breath sequences: CMV, IMV, and CSV.

(8) Ventilators deliver 5 basic ventilatory patterns: VC-CMV, VCIMV, PC-CMV, PC-IMV, and PC-CSV.

(9) Within each ventilatory pattern, there are several types that can be distinguished by their targeting schemes (set-point, dual, biovariable, servo, adaptive, optimal, and intelligent).

(10) A mode of ventilation is classified according to its control variable, breath sequence, and targeting schemes.

$\mathrm{CMV}=$ continuous mandatory ventilation

IMV $=$ intermittent mandatory ventilation

$\mathrm{CSV}=$ continuous spontaneous ventilation

$\mathrm{VC}=$ volume control

$\mathrm{PC}=$ pressure control

istics) using a simple structured approach to teaching and learning the fundamental principles of ventilator operation. This taxonomy has recently been adopted by the ECRI (formerly the Emergency Care Research Institute) for describing and comparing ventilators. ${ }^{6}$ We do not discuss clinical application, but rather the technology that is the foundation for clinical application. This is a topic that we believe is not sufficiently discussed in current textbooks. We have developed this system over many years of clinical experience and instruction of medical students, physicians, and respiratory therapists in both the hospital and university environments. It is based on what we consider to be 10 fundamental theoretical constructs or maxims (Table 1) that are recognizable to most people familiar with mechanical ventilation. ${ }^{7}$ We demonstrate how these 10 maxims form the basis of the taxonomy. We also show how the taxonomy is a practical tool for dealing with the complexity represented by the many mode names mentioned above. Figure 1 illustrates a hierarchy of skills we believe must be mastered before one is fully able to use mechanical ventilation technology as suggested by the AARC competency statements. Note that this hierarchy is consistent with Bloom's revised taxonomy of learning objectives (a classification of levels of intellectual behavior important in learning). ${ }^{8}$ 


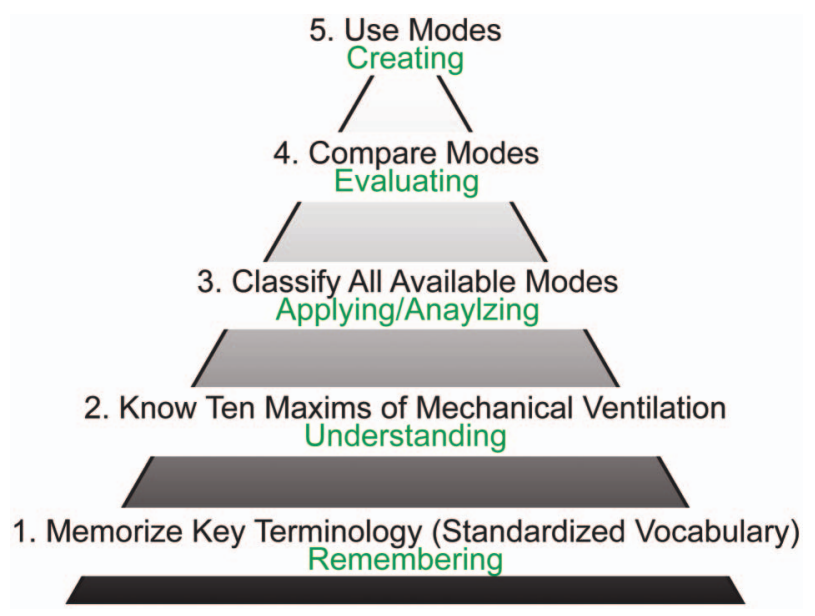

Fig. 1. Pyramid of skills required to master ventilator technology. The terms in green are from Bloom's revised taxonomy of learning objectives.

\section{What Is a Mode of Mechanical Ventilation?}

A mode of mechanical ventilation may be defined, in general, as a predetermined pattern of patient-ventilator interaction. It is constructed using 3 basic components: (1) the ventilator breath control variable, (2) the breath sequence, and (3) the targeting scheme (Fig. 2) To understand each of these components, we use the maxims that form the basis for the taxonomy of mechanical ventilation. These 10 maxims describe, in a progressive manner, the rationale of how we classify modes by understanding what a mode does. Maxims 1-3 explain the ventilator breath control variable. Maxims 4-8 explain the breath sequence. Maxim 9 explains the targeting schemes. Maxim 10 pulls together the previous maxims to formulate the complete taxonomy.

\section{The 10 Maxims}

The following sections describe the 10 theoretical constructs that we believe form the basis of a practical syllabus for learning mechanical ventilation technology. They also provide the context for some basic definitions of terms used to construct a standardized vocabulary (see the supplementary materials at http://www.rcjournal.com). We start with very simple, intuitively obvious ideas and then build on these concepts to form a theoretical framework for understanding and using ventilators.

(1) A breath is one cycle of positive flow (inspiration) and negative flow (expiration) defined in terms of the flowtime curve. A breath is defined in terms of the flow-time curve (Fig. 3). By convention, positive flow (ie, values of flow above zero) is designated as inspiration. Negative flow (values below zero) indicates expiration. Inspiratory time is defined as the period from the start of positive flow to the start of negative flow. Expiratory time is defined as the period from the start of negative flow to the start of positive flow. Total cycle time (also called the ventilatory period) is the sum of inspiratory and expiratory times. It is also equal to the inverse of breathing frequency (total cycle time $=1 /$ frequency, usually expressed as $60 \mathrm{~s} /$ breaths/ $\mathrm{min})$. The inspiratory-expiratory ratio is defined as the ratio of inspiratory time to expiratory time. The duty cycle (or percent inspiration) is defined as the ratio of inspiratory time to total cycle time. The tidal volume $\left(\mathrm{V}_{\mathrm{T}}\right)$ is the integral of flow with respect to time. For constant flow inspiration, this simply reduces to the product of flow and inspiratory time.

(2) A breath is assisted if the ventilator provides some or all of the work of breathing. An assisted breath is one for which the ventilator does some portion of the work of breathing. This work may be defined, for example, as the integral of inspiratory transrespiratory pressure with respect to inspired volume. Graphically, this corresponds to airway pressure increasing above baseline during inspiration. Increased work of breathing per breath, as a result of increased resistive and/or elastic work, is characterized by increased transrespiratory pressure (for a definition of transrespiratory pressure, see the supplementary materials at http://www. rcjournal.com). In contrast, a loaded breath is one for which transrespiratory pressure decreases below baseline during inspiration $^{9}$ and is interpreted as the patient doing work on the ventilator (eg, to start inspiration).

A ventilator provides all of the mechanical work of inspiration (ie, full support) only if the patient's inspiratory muscles are inactive (eg, drug-induced neuromuscular blockade). An unassisted breath is one for which the ventilator simply provides flow at the rate required by the patient's inspiratory effort, and transrespiratory system pressure stays constant throughout the breath. An example of this would be CPAP delivered with a demand valve. A ventilator can assist expiration by making the transrespiratory pressure fall below baseline during expiration. An example of this is automatic tube compensation on the Evita XL ventilator (Dräger, Lübeck, Germany). When tube compensation is activated, the ventilation pressure in the breathing circuit is increased during inspiration or decreased during expiration. The airway pressure is adjusted to the tracheal level if $100 \%$ compensation of the tube resistance has been selected. Another example is the use of a cough-assist device (eg, CoughAssist mechanical insufflator-exsufflator, Philips Respironics, Murrysville, Pennsylvania). In this case, transrespiratory pressure goes negative during expiration because pressure on the body surface is increased while pressure at the mouth remains at atmospheric pressure.

(3) A ventilator assists breathing using either pressure control or volume control based on the equation of motion for the respiratory system. The theoretical framework for understanding control variables is the equation of motion 


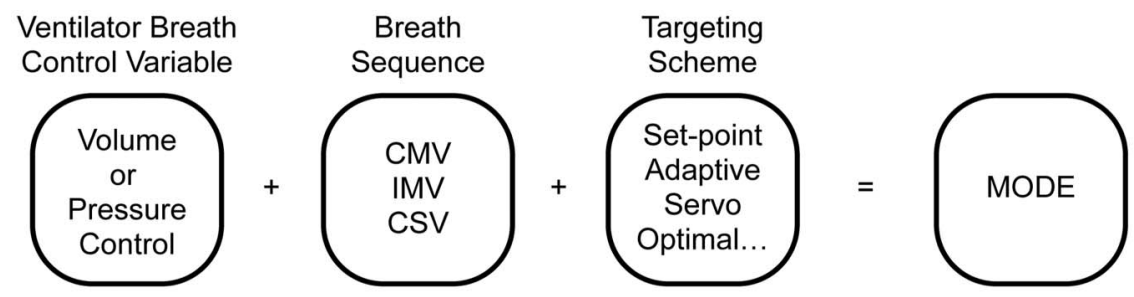

Fig. 2. Building blocks for constructing a mode. CMV = continuous mandatory ventilation; IMV = intermittent mandatory ventilation; CSV $=$ continuous spontaneous ventilation.

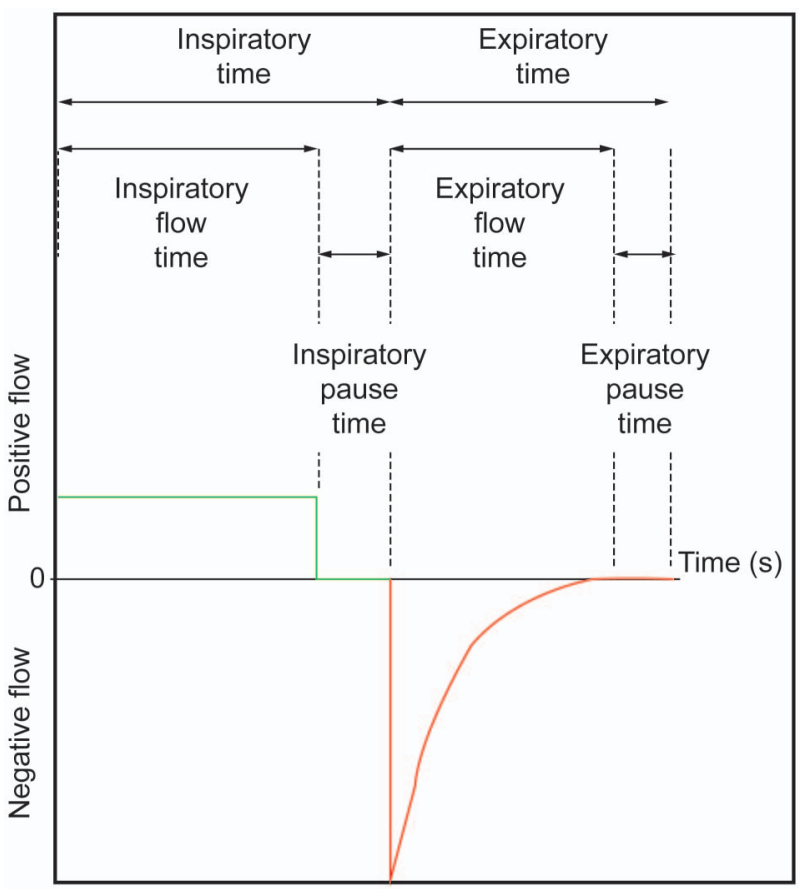

Fig. 3. A breath is defined in terms of the flow-time curve. Important timing parameters related to ventilator settings are labeled.

for the passive respiratory system: $\mathrm{P}(\mathrm{t})=\mathrm{EV}(\mathrm{t})+\mathrm{R} \dot{\mathrm{V}}(\mathrm{t})$. This equation relates pressure $(\mathrm{P})$, volume $(\mathrm{V})$, and flow $(\mathrm{V})$ as continuous functions of time (t) with the parameters of elastance (E) and resistance (R). If any one of the functions $(\mathrm{P}, \mathrm{V}$, or $\dot{\mathrm{V}})$ is predetermined, the other two may be derived. The control variable refers to the function that is controlled (predetermined) during a breath (inspiration). This form of the equation assumes that the patient makes no inspiratory effort and that expiration is complete (no auto-PEEP).

Volume control (VC) means that both volume and flow are pre-set prior to inspiration. Setting the $V_{T}$ is a necessary but not sufficient criterion for declaring volume control because some modes of pressure control allow the operator to set a target $\mathrm{V}_{\mathrm{T}}$ but allow the ventilator to determine the flow (see adaptive targeting scheme below). Similarly, setting flow is also a necessary but not sufficient criterion. Some pressure control modes allow the operator to set the maximum inspiratory flow, but the $\mathrm{V}_{\mathrm{T}}$ depends on the inspiratory pressure target and respiratory system mechanics.

Pressure control (PC) means that inspiratory pressure as a function of time is predetermined. In practice, this currently means pre-setting a particular pressure waveform (eg, $\mathrm{P}(\mathrm{t})=$ constant), or inspiratory pressure is set to be proportional to patient inspiratory effort, measured by various means. For example, $\mathrm{P}(\mathrm{t})=$ NAVA level $\times$ EAdi $(\mathrm{t})$, where NAVA stands for neurally adjusted ventilatory assist, and EAdi stands for electrical activity of the diaphragm (see servo targeting scheme below). In a passive patient, after setting the form of the pressure function (ie, the waveform), volume and flow depend on elastance and resistance. ${ }^{10}$

Time control is a general category of ventilator modes for which inspiratory flow, inspiratory volume, and inspiratory pressure are all dependent on respiratory system mechanics. As no parameters of the pressure, volume, or flow waveforms are pre-set, the only control of the breath is the timing (ie, inspiratory and expiratory times). Examples of this are high-frequency oscillatory ventilation (3100 ventilator, CareFusion, San Diego, California) and volumetric diffusive respiration (Percussionaire, Sagle, Idaho).

(4) Breaths are classified according to the criteria that trigger (start) and cycle (stop) inspiration. Inspiration starts (or is triggered) when a monitored variable (trigger variable) achieves a pre-set threshold (the trigger event). The simplest trigger variable is time, as in the case of a pre-set breathing frequency (recall that the period between breaths is 1 /frequency). Other trigger variables include a minimum level of minute ventilation, a pre-set apnea interval, or various indicators of inspiratory effort (eg, changes in baseline pressure or flow or electrical signals derived from diaphragm movement).

Inspiration stops (or is cycled off) when a monitored variable (cycle variable) achieves a pre-set threshold (cycle event). The simplest cycle variable is a pre-set inspiratory time. Other cycle variables include pressure (eg, peak airway pressure), volume (eg, $\mathrm{V}_{\mathrm{T}}$ ), flow (eg, percent of peak inspiratory flow), and electrical signals derived from diaphragm movement. 
(5) Trigger and cycle events can be either patient-initiated or ventilator-initiated. Inspiration can be patienttriggered or patient-cycled by a signal representing inspiratory effort (eg, changes in baseline airway pressure, changes in baseline bias flow, or electrical signals derived from diaphragm activity, as with neurally adjusted ventilatory assist ${ }^{11}$ or a calculated estimate of muscle pressure $^{12}$ ). Furthermore, the ventilator can be triggered and cycled solely by the patient's passive respiratory system mechanics (elastance and resistance). ${ }^{13}$ For example, an increase in elastance or resistance in some modes will increase airway pressure beyond the alarm threshold and cycle inspiration. Inspiration may be ventilator-triggered or ventilator-cycled by pre-set thresholds.

Patient triggering means starting inspiration based on a patient signal, independent of a ventilator-generated trigger signal. Ventilator triggering means starting inspiratory flow based on a signal (usually time) from the ventilator, independent of a patient-triggered signal. Patient cycling means ending inspiratory time based on signals representing the patient-determined components of the equation of motion (ie, elastance or resistance and including effects due to inspiratory effort). Flow cycling is a form of patient cycling because the rate of flow decay to the cycle threshold (and hence, the inspiratory time) is determined by patient mechanics (ie, the time constant and effort). Ventilator cycling means ending inspiratory time independent of signals representing the patient-determined components of the equation of motion.

As a further refinement, patient triggering can be defined as starting inspiration based on a patient signal occurring in a trigger window, independent of a ventilatorgenerated trigger signal. A trigger window is the period composed of the entire expiratory time minus a short refractory period required to reduce the risk of triggering a breath before exhalation is complete (Fig. 4). If a signal from the patient (ie, some measured variable indicating an inspiratory effort) occurs within this trigger window, inspiration starts and is defined as a patient-triggered event.

A synchronization window is a short period, at the end of a pre-set expiratory or inspiratory time, during which a patient signal may be used to synchronize the beginning or ending of inspiration to the patient's actions. If the patient signal occurs during an expiratory time synchronization window, inspiration starts and is defined as a ventilatortriggered event initiating a mandatory breath. This is because the mandatory breath would have been time-triggered regardless of whether the patient signal had appeared or not and because the distinction is necessary to avoid logical inconsistencies in defining mandatory and spontaneous breaths (see below), which are the foundation of the mode taxonomy. Trigger and synchronization windows are another way to distinguish between continuous mandatory ventilation (CMV) and intermittent mandatory ven-
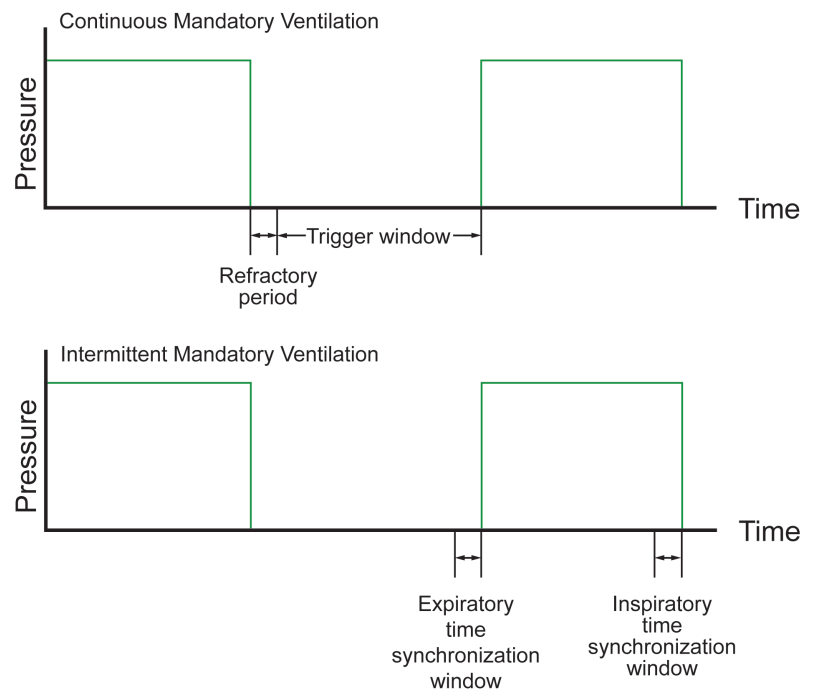

Fig. 4. Trigger and synchronization windows. If a patient signal occurs within the trigger window, inspiration is patient-triggered. If a patient signal occurs within a synchronization window, inspiration is ventilator-triggered (or cycled if at the end of inspiration) and patient-synchronized. Note that, in general, a trigger window is used with continuous mandatory ventilation, a synchronization window is used with intermittent mandatory ventilation.

tilation (IMV) (see below). Sometimes a synchronization window is used at the end of the inspiratory time of a pressure control, time-cycled breath. If the patient signal occurs during such an inspiratory time synchronization window, expiration starts and is defined as a ventilatorcycled event, ending a mandatory breath.

Some ventilators offer the mode called airway pressure release ventilation (or something similar with a different name), which may use both expiratory and inspiratory synchronization windows. This mode is an example of the importance of distinguishing between trigger/cycle windows (allowing for patient-triggered breaths) and synchronization windows (allowing for patient-synchronized, ventilator-triggered breaths). Airway pressure release ventilation is intended to provide a set number of so-called releases or drops from a high-pressure level to a lowpressure level. Spontaneous breaths are possible at the high-pressure and low-pressure levels (although there may not be enough time to accomplish this if the duration of the low pressure is too short). Using the standardized vocabulary we have been discussing, these releases (paired with their respective rises) are actually mandatory breaths because they are time-triggered and time-cycled. On some ventilators, synchronization windows were added to both the expiratory time (to synchronize the transition to high pressure with a patient inspiratory effort) and the inspiratory time (to synchronize cycling with the expiratory phase of a spontaneous breath taken during the high-pressure level). If both triggering and cycling occurred with patient signals in the synchronization window, and if we called 


\begin{abstract}
${ }^{1}$ Period comprised of expiratory time minus short refractory period to reduce risk of starting next breath before exhalation is complete.
\end{abstract}

${ }^{2}$ Short period at the end of preset expiratory time or preset inspiratory time.

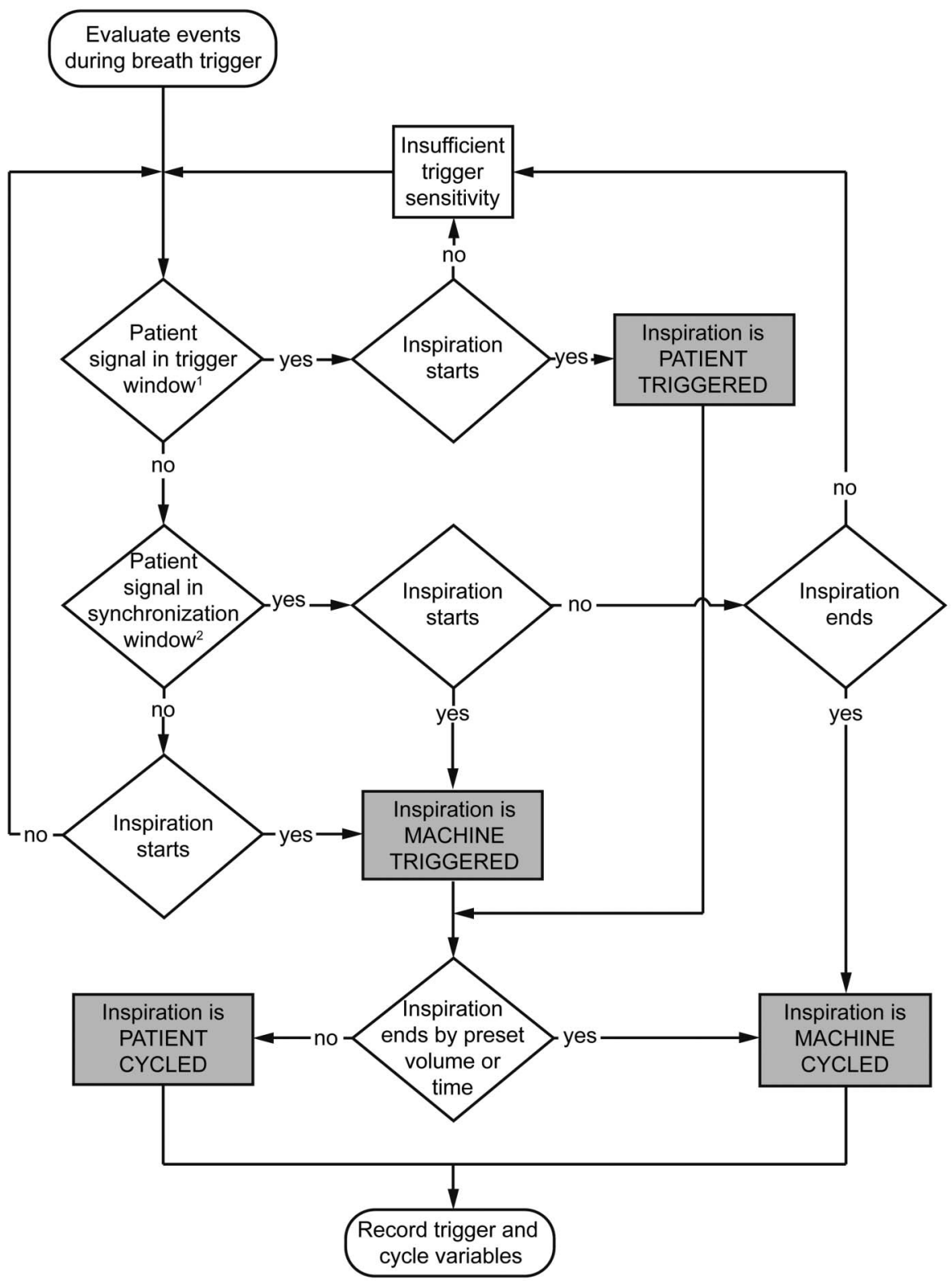

Fig. 5. Rubric for classifying trigger and cycle events. Courtesy Mandu Press.

these events patient-triggered and patient cycled, then we would end up with the ambiguous possibility of having spontaneous breaths (ie, synchronized) occurring during spontaneous breaths (unsynchronized breaths during the high-pressure level). Another example occurs with a ventilator such as the CareFusion Avea, which allows the operator to set a flow cycle criterion for pressure control PC-IMV. Thus, every inspiration is patient-cycled, and if we said that any synchronized breaths (synchronized IMV) were patient-triggered, we would be implying that these mandatory breaths were really spontaneous breaths. This would be misleading because the pre-set mandatory breathing frequency would then be larger than what we count as mandatory breaths when observing the patient. On modes that are classified as forms of IMV (such as airway pressure release ventilation), we need to distinguish between the mandatory minute ventilation and the spontaneous minute ventilation (to gauge the level of mechanical support), and we cannot do this if the definitions of mandatory and spontaneous breaths are in any way ambiguous. Figure 5 shows the decision rubric for classifying trigger and cycle events.

(6) Breaths are classified as spontaneous or mandatory based on both the trigger and cycle events. A spontaneous breath is a breath for which the patient retains control over timing. This means that the start and end of inspiration are 
determined by the patient, independent of any ventilator settings for inspiratory and expiratory times. That is, the patient both triggers and cycles the breath. A spontaneous breath may occur during a mandatory breath (eg, airway pressure release ventilation). A spontaneous breath may be assisted or unassisted. Indeed, the definition of a spontaneous breath applies to normal breathing as well as mechanical ventilation. Some authors use the term spontaneous breath to refer only to unassisted breaths, but that is an unnecessary limitation that prevents the word from being used as a key term in the mode taxonomy.

A mandatory breath is a breath for which the patient has lost control over timing (ie, frequency or inspiratory time). This is a breath for which the start or end of inspiration (or both) is determined by the ventilator, independent of the patient: the ventilator triggers and/or cycles the breath. A mandatory breath can occur during a spontaneous breath (eg, high-frequency jet ventilation). A mandatory breath is, by definition, assisted.

(7) Ventilators deliver 3 basic breath sequences: CMV, $I M V$, and continuous spontaneous ventilation CSV. A breath sequence is a particular pattern of spontaneous and/or mandatory breaths. The 3 possible breath sequences are CMV, IMV, and CSV. CMV, commonly known as assist control, is a breath sequence for which spontaneous breaths are not possible between mandatory breaths because every patient-triggered signal in the trigger window produces a ventilator-cycled inspiration (ie, a mandatory breath). IMV is a breath sequence for which spontaneous breaths are possible between mandatory breaths. Ventilator-triggered mandatory breaths may be delivered at a pre-set frequency. The mandatory breathing frequency for CMV may be higher than the set frequency but never below it (ie, the set frequency is a minimum value). In some pressure control modes on ventilators with an active exhalation valve, spontaneous breaths may occur during mandatory breaths, but the defining characteristic of CMV is that spontaneous breaths are not permitted between mandatory breaths. In contrast, the set frequency of mandatory breaths for IMV is the maximum value because every patient signal between mandatory breaths initiates a spontaneous breath.

There are 3 variations of IMV. (1) Mandatory breaths are always delivered at the set frequency (eg, SIMV volume control mode on the PB840 ventilator, Covidien, Mansfield, Massachusetts). In general, if a synchronization window is used, the actual ventilatory period for a mandatory breath may be shorter than the set period. Some ventilators will add the difference to the next mandatory period to maintain the set mandatory breathing frequency (eg, Dräger Evita XL ventilator). (2) Mandatory breaths are delivered only when the spontaneous breathing frequency falls below the set frequency (eg, BiPAP [bi-level positive airway pressure] S/T mode on the Philips Respironics V60 ventilator). In other words, spontaneous breaths may suppress mandatory breaths. (3) Mandatory breaths are delivered only when the measured minute ventilation (ie, product of breathing frequency and $\mathrm{V}_{\mathrm{T}}$ ) drops below a pre-set threshold (examples include Dräger's mandatory minute volume ventilation mode and Hamilton Medical's adaptive support ventilation mode). Again, in this form of IMV, spontaneous breaths may suppress mandatory breaths.

(8) Ventilators deliver 5 basic ventilatory patterns: volume control VC-CMV, VC-IMV, PC-CMV, PC-IMV, and $P C$-CSV. A ventilatory pattern is a sequence of breaths (CMV, IMV, or CSV) with a designated control variable (volume or pressure) for the mandatory breaths (or the spontaneous breaths for CSV). Thus, with 2 control variables and 3 breath sequences, there are 5 possible ventilatory patterns: VC-CMV, VC-IMV, PC-CMV, PC-IMV, and PC-CSV. The VC-CSV combination is not possible because volume control implies ventilator cycling, and ventilator cycling makes every breath mandatory, not spontaneous (maxim 6). For completeness, we should also include the possibility of a time control ventilatory pattern such as time control IMV. Although this is uncommon and nonconventional, it is possible, as demonstrated by modes such as high-frequency oscillatory ventilation and intrapulmonary percussive ventilation. Because any mode of ventilation can be associated with one and only one ventilatory pattern, the ventilatory pattern serves as a simple mode classification system.

(9) Within each ventilatory pattern, there are several types that can be distinguished by their targeting schemes (set-point, dual, bio-variable, servo, adaptive, optimal, and intelligent). A targeting scheme is a model ${ }^{14}$ of the relationship between operator inputs and ventilator outputs to achieve a specific ventilatory pattern, usually in the form of a feedback control system. A target is a predetermined goal of ventilator output. Targets can be viewed as the goals of the targeting scheme. Targets can be set for parameters during a breath (within-breath targets). These parameters relate to the pressure, volume, and flow waveforms. Examples of within-breath targets include peak inspiratory flow and $\mathrm{V}_{\mathrm{T}}$ or inspiratory pressure and rise time (set-point targeting); pressure, volume, and flow (dual targeting); and constant of proportionality between inspiratory pressure and patient effort (servo targeting).

Targets can be set between breaths to modify the within-breath targets and/or the overall ventilatory pattern (between-breath targets). These are used with more advanced targeting schemes, where targets act over multiple breaths. Examples of between-breath targets and targeting schemes include average $\mathrm{V}_{\mathrm{T}}$ (for adaptive targeting using pressure control); work rate of breathing and minute ventilation (for optimal targeting); and combined end-tidal $\mathrm{P}_{\mathrm{CO}_{2}}$, volume, and frequency values describing a zone of comfort (for intelligent targeting, eg, SmartCare/PS [Dräger Evita In- 
finity V500] or IntelliVent-ASV [S1 ventilator, Hamilton Medical, Reno, Nevada]).

The targeting scheme (or combination of targeting schemes) is what distinguishes one ventilatory pattern from another. There are currently 7 basic targeting schemes that comprise the wide variety seen in different modes of ventilation. (1) Set-point is a targeting scheme for which the operator sets all of the parameters of the pressure waveform (pressure control modes) or volume and flow waveforms (volume control modes). (2) Dual is a targeting scheme that allows the ventilator to switch between volume control and pressure control during a single inspiration. (3) Bio-variable is a targeting scheme that allows the ventilator to automatically set the inspiratory pressure (or $\mathrm{V}_{\mathrm{T}}$ ) randomly to mimic the variability observed during normal breathing. (4) Servo is a targeting scheme for which the output of the ventilator (eg, inspiratory pressure) automatically follows a varying input (eg, inspiratory effort). (5) Adaptive is a targeting scheme that allows the ventilator to automatically set one target (eg, pressure within a breath) to achieve another target (eg, average $\mathrm{V}_{\mathrm{T}}$ over several breaths). (6) Optimal is a targeting scheme that automatically adjusts the targets of the ventilatory pattern to either minimize or maximize some overall performance characteristic (eg, work rate of breathing). (7) Intelligent is a targeting scheme that automatically adjusts the targets of the ventilatory pattern using artificial intelligence programs such as fuzzy logic, rule-based expert systems, and artificial neural networks.

(10) A mode of ventilation is classified according to its control variable, breath sequence, and targeting scheme(s). The preceding 9 maxims create a theoretical foundation for the taxonomy of mechanical ventilation. Taxonomy is the science of classification. A full explanation of how taxonomies are created, as it applies to mechanical ventilation, has been published previously. ${ }^{15}$ In short, the first step is to create a standardized set of definitions. We have refined such a vocabulary over the last 20 years (see the supplementary materials at http://www.rcjournal.com). Selected terms in the vocabulary are used to create a hierarchical classification system (essentially an outline) that forms the structure of the taxonomy.

The taxonomy has 4 hierarchical levels (analogous to order, class, genus, and species used in biological taxonomies): (1) control variable (pressure or volume, for the primary breath), (2) breath sequence (for CMV, IMV, or CSV), (3) primary breath targeting scheme (for CMV, IMV, or CSV), and (4) secondary breath targeting scheme (for IMV). The primary breath is either the only breath that occurs (mandatory breaths in CMV and spontaneous breaths in CSV) or the mandatory breath in IMV. We consider it primary because if the patient becomes apneic, it is the only thing keeping the patient alive.
The targeting schemes can be represented by single lowercase letters: set-point $=\mathrm{s}$, dual $=\mathrm{d}$, servo $=\mathrm{r}$, biovariable $=\mathrm{b}$, adaptive $=\mathrm{a}$, optimal $=\mathrm{o}$, and intelligent $=$ i. For example, on the Covidien PB840 ventilator, there is a mode called $\mathrm{A} / \mathrm{C}$ volume control (volume assist control). This mode is classified as VC-CMV with set-point targeting, represented by VC-CMVs.

Minor differences in a species of modes (such as unique operational algorithms) can be accommodated by adding a fifth level we could call variety (as is done in biology). As an example, there are 3 varieties of PC-CSV using servo targeting. One makes inspiratory pressure proportional to the square of inspiratory flow (automatic tube compensation), one makes it proportional to the electrical signal from the diaphragm (neurally adjusted ventilatory assist), and one makes it proportional to the patient-generated volume and flow (proportional assist ventilation). The first can support only the resistive load of breathing, whereas the other two can support both the elastic and resistive loads.

\section{Application of the Taxonomy}

Translating a name of a mode into a mode classification using the taxonomy is a simple 3 -step procedure. In step 1 , the primary breath control variable is identified. Simply put, if inspiratory pressure is set or if pressure is proportional to inspiratory effort, then the control variable is pressure. In contrast, if the $\mathrm{V}_{\mathrm{T}}$ and inspiratory flow are set, then the control variable is volume. Figure 6 shows the decision rubric with a few refinements to accommodate dual targeting. In step 2, the breath sequence is identified. Figure 7 shows the decision rubric. In step 3, the targeting schemes for the primary and, if applicable, secondary breaths are identified (Table 2).

\section{Examples}

To demonstrate these steps, we will classify some of the most commonly used modes in ICUs, starting with A/C volume control (Covidien PB840 ventilator). For this mode, both inspiratory volume and flow are pre-set, so the control variable is volume (see Fig. 6). Every breath is volume-cycled, which is a form of ventilator cycling. Any breath for which inspiration is ventilator-cycled is classified as a mandatory breath. Hence, the breath sequence is CMV (see Fig. 7). Finally, the operator sets all of the parameters of the volume and flow waveforms, so the targeting scheme is set-point (see Table 2). Thus, the mode is classified as VC-CMV with set-point targeting (VCCMVs).

Another common mode is SIMV volume control plus (Covidien PB840 ventilator). For this mode, the operator sets the $\mathrm{V}_{\mathrm{T}}$, but not inspiratory flow. Because setting vol- 


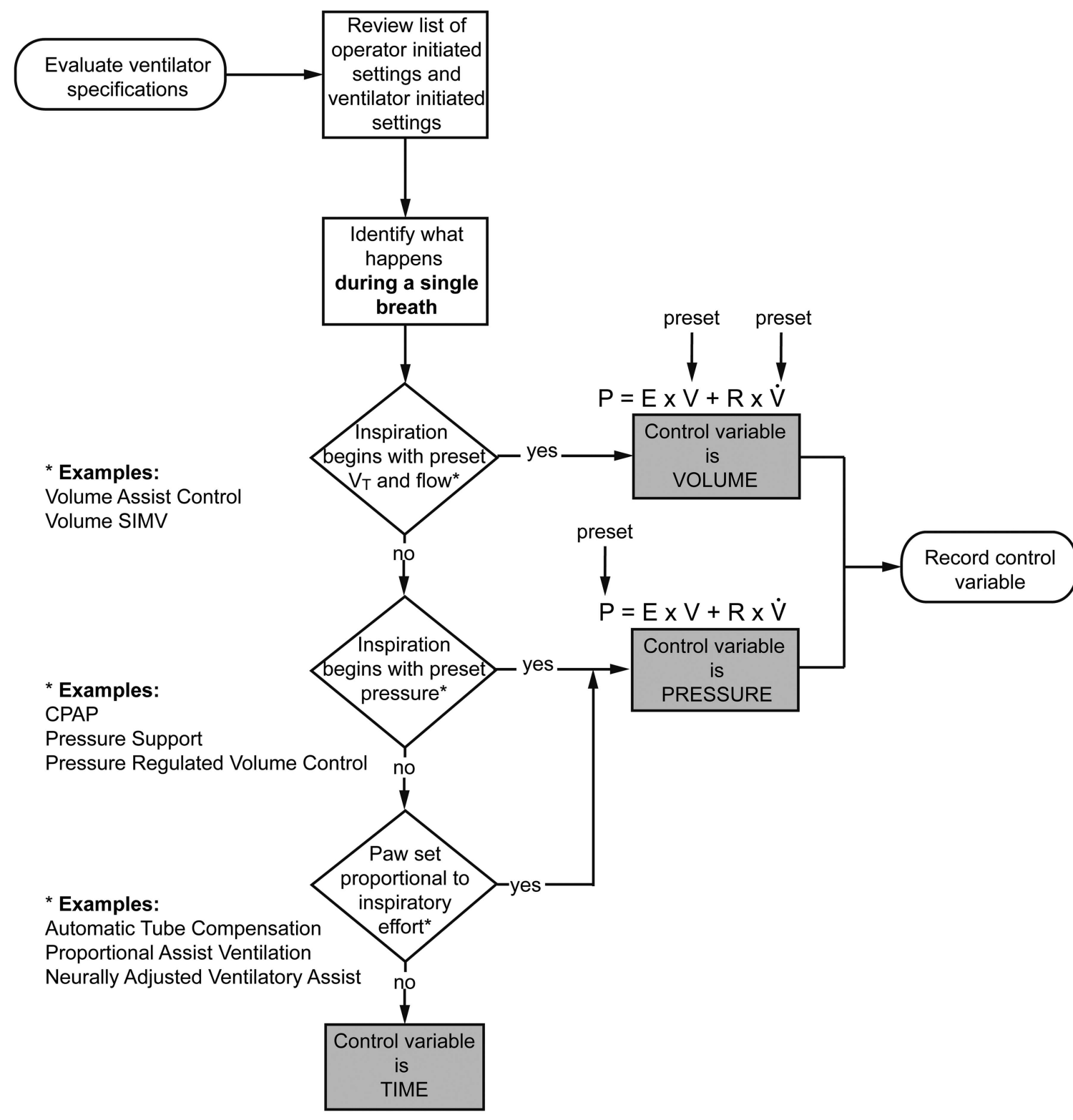

Example:

Intrapulmonary Percussive Ventilation

Fig. 6. Rubric for determining the control variable of a mode. Paw = airway pressure, SIMV = synchronized intermittent mandatory ventilation; $\mathrm{V}_{\mathrm{T}}=$ tidal volume; $\mathrm{P}=$ pressure; $\mathrm{E}=$ elastance; $\mathrm{V}=$ volume; $\mathrm{R}=$ resistance; $\dot{\mathrm{V}}=$ inspiratory flow. Courtesy Mandu Press.

ume alone (like setting flow alone) is a necessary but not sufficient criterion for volume control, the control variable is pressure (see Fig. 6). Spontaneous breaths are allowed between mandatory breaths, so the breath sequence is IMV (see Fig. 7). The ventilator adjusts inspiratory pressure for mandatory breaths to achieve an average pre-set $\mathrm{V}_{\mathrm{T}}$, so the targeting scheme for the mandatory breaths is adaptive (see Table 2). For spontaneous breaths, inspiratory pressure is set by the operator (eg, pressure support), so the targeting scheme for these breaths is set-point. The mode tag is PC-IMVa,s.

A very common mode for spontaneous breathing trials (or for assistance of spontaneous breaths in IMV modes) is pressure support or pressure support ventilation (note that although ubiquitous, pressure support is a name, not a classification). For this mode, the operator sets an inspiratory pressure, so the control variable is pressure. All breaths are patient-triggered and patient-cycled (note that flow cy- 


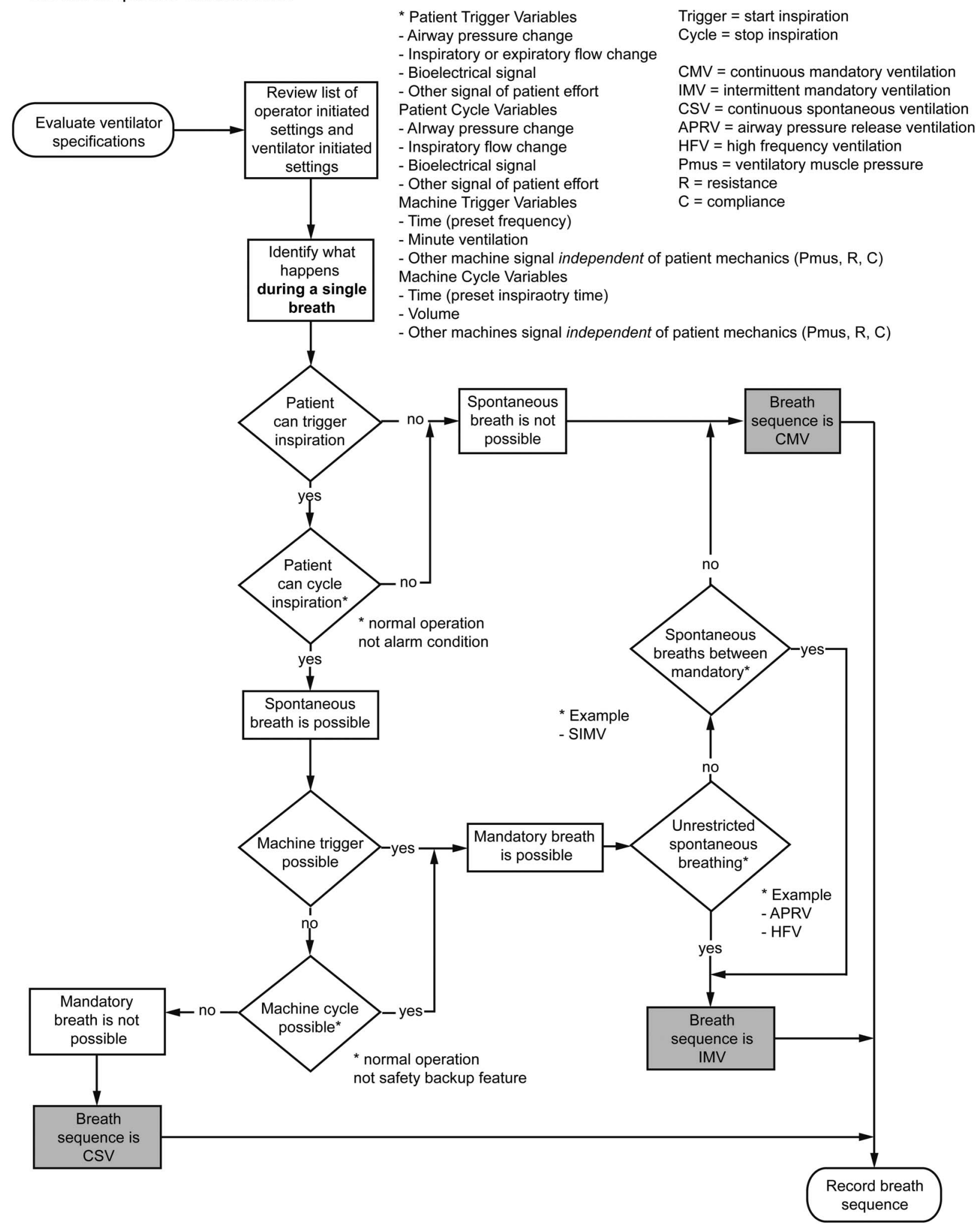

Fig. 7. Rubric for determining the breath sequence of a mode. Courtesy Mandu Press. 
TAXonomy for Mechanical Ventilation

Table 2. Targeting Schemes

\begin{tabular}{|c|c|c|c|c|c|}
\hline $\begin{array}{c}\text { Name } \\
\text { (Abbreviation) }\end{array}$ & Description & Advantage & Disadvantage & Example Mode Name & $\begin{array}{c}\text { Ventilator } \\
\text { (Manufacturer) }\end{array}$ \\
\hline Set-point (s) & $\begin{array}{l}\text { The operator sets all } \\
\text { parameters of the pressure } \\
\text { waveform (pressure control } \\
\text { modes) or volume and flow } \\
\text { waveforms (volume control } \\
\text { modes). }\end{array}$ & Simplicity & $\begin{array}{l}\text { Changing patient conditions } \\
\text { may make settings } \\
\text { inappropriate. }\end{array}$ & Volume control CMV & $\begin{array}{l}\text { Evita Infinity V500 } \\
\text { (Dräger) }\end{array}$ \\
\hline Dual (d) & $\begin{array}{l}\text { The ventilator can } \\
\text { automatically switch } \\
\text { between volume control } \\
\text { and pressure control during } \\
\text { a single inspiration. }\end{array}$ & $\begin{array}{l}\text { It can adjust to changing } \\
\text { patient conditions and } \\
\text { ensure either a pre-set } \\
\mathrm{V}_{\mathrm{T}} \text { or peak inspiratory } \\
\text { pressure, whichever is } \\
\text { deemed most important. }\end{array}$ & $\begin{array}{l}\text { It may be complicated to } \\
\text { set correctly and may } \\
\text { need constant } \\
\text { readjustment if not } \\
\text { automatically controlled } \\
\text { by the ventilator. }\end{array}$ & Volume control & Servo-i (Maquet) \\
\hline Servo (r) & $\begin{array}{l}\text { The output of the ventilator } \\
\text { (pressure/volume/flow) } \\
\text { automatically follows a } \\
\text { varying input. }\end{array}$ & $\begin{array}{l}\text { Support by the ventilator is } \\
\text { proportional to } \\
\text { inspiratory effort. }\end{array}$ & $\begin{array}{l}\text { It requires estimates of } \\
\text { artificial airway and/or } \\
\text { respiratory system } \\
\text { mechanical properties. }\end{array}$ & $\begin{array}{l}\text { Proportional assist } \\
\text { ventilation plus }\end{array}$ & PB840 (Covidien) \\
\hline Adaptive (a) & $\begin{array}{l}\text { The ventilator automatically } \\
\text { sets target(s) between } \\
\text { breaths in response to } \\
\text { varying patient conditions. }\end{array}$ & $\begin{array}{l}\text { It can maintain stable } \mathrm{V}_{\mathrm{T}} \\
\text { delivery with pressure } \\
\text { control for changing } \\
\text { lung mechanics or } \\
\text { patient inspiratory effort. }\end{array}$ & $\begin{array}{l}\text { Automatic adjustment may } \\
\text { be inappropriate if } \\
\text { algorithm assumptions } \\
\text { are violated or if they do } \\
\text { not match physiology. }\end{array}$ & $\begin{array}{l}\text { Pressure-regulated } \\
\text { volume control }\end{array}$ & Servo-i \\
\hline Bio-variable (b) & $\begin{array}{l}\text { The ventilator automatically } \\
\text { adjusts the inspiratory } \\
\text { pressure or } \mathrm{V}_{\mathrm{T}} \text { randomly. }\end{array}$ & $\begin{array}{l}\text { It simulates the variability } \\
\text { observed during normal } \\
\text { breathing and may } \\
\text { improve oxygenation or } \\
\text { mechanics. }\end{array}$ & $\begin{array}{l}\text { Manually set range of } \\
\text { variability may be } \\
\text { inappropriate to achieve } \\
\text { goals. }\end{array}$ & $\begin{array}{l}\text { Variable pressure } \\
\text { support }\end{array}$ & Evita Infinity V500 \\
\hline Optimal (o) & $\begin{array}{l}\text { The ventilator automatically } \\
\text { adjusts the targets of the } \\
\text { ventilatory pattern to either } \\
\text { minimize or maximize } \\
\text { some overall performance } \\
\text { characteristic (eg, work rate } \\
\text { of breathing). }\end{array}$ & $\begin{array}{l}\text { It can adjust to changing } \\
\text { lung mechanics or } \\
\text { patient inspiratory effort. }\end{array}$ & $\begin{array}{l}\text { Automatic adjustment may } \\
\text { be inappropriate if } \\
\text { algorithm assumptions } \\
\text { are violated or if they do } \\
\text { not match physiology. }\end{array}$ & ASV & $\begin{array}{l}\text { G5 (Hamilton } \\
\text { Medical) }\end{array}$ \\
\hline Intelligent (i) & $\begin{array}{l}\text { This is a targeting scheme } \\
\text { that uses artificial } \\
\text { intelligence programs such } \\
\text { as fuzzy logic, rule-based } \\
\text { expert systems, and } \\
\text { artificial neural networks. }\end{array}$ & $\begin{array}{l}\text { It can adjust to changing } \\
\text { lung mechanics or } \\
\text { patient inspiratory effort. }\end{array}$ & $\begin{array}{l}\text { Automatic adjustment may } \\
\text { be inappropriate if } \\
\text { algorithm assumptions } \\
\text { are violated or if they do } \\
\text { not match physiology. }\end{array}$ & $\begin{array}{l}\text { SmartCare/PS } \\
\text { IntelliVent-ASV }\end{array}$ & $\begin{array}{l}\text { Evita Infinity V500 } \\
\text { S1 (Hamilton } \\
\text { Medical) }\end{array}$ \\
\hline \multicolumn{6}{|c|}{$\begin{array}{l}\text { CMV = continuous mandatory ventilation } \\
\text { ASV = adaptive support ventilation }\end{array}$} \\
\hline
\end{tabular}

cling is a form of patient cycling, as discussed above), so the breath sequence is CSV. Because the ventilator does not automatically adjust any of the parameters of the breath, the targeting scheme is set-point, and the tag is PC-CSVs.

If carefully applied, the taxonomy has the power to clarify and unmask hidden complexity in a mode that has a cryptic name. Take, for example, the mode called CMV + AutoFlow on the Dräger Evita XL ventilator. Although CMV on this ventilator is a mode equivalent to volume assist control (described above), adding the AutoFlow feature changes it to a completely different mode. For CMV + AutoFlow, the operator sets a target $\mathrm{V}_{\mathrm{T}}$, but not inspiratory flow. Indeed, inspiratory flow is highly variable because the ventilator automatically sets the inspiratory pressure within a breath. Thus, according to the equation of motion, the control variable is pressure. Every inspiration is time-cycled and hence mandatory, and the breath sequence is CMV. The ventilator adjusts the inspiratory pressure between breaths to achieve an average
$\mathrm{V}_{\mathrm{T}}$ equal to the pre-set value using an adaptive targeting scheme. Thus, the mode is classified as PC-CMV with adaptive targeting (PC-CMVa).

On the other hand, the taxonomy can unmask the complexity in an apparently simple mode. The mode called volume control (Servo-i, Maquet, Wayne, New Jersey) allows setting the $\mathrm{V}_{\mathrm{T}}$ and inspiratory time. Setting both volume and inspiratory time is equivalent to setting mean inspiratory flow (flow = volume/time); hence, the control variable is volume. Every breath is normally time-cycled and hence mandatory, so our initial thought is that the breath sequence is CMV. The tricky part is the targeting scheme. The operator's manual states that ". . . if a pressure drop of $3 \mathrm{~cm} \mathrm{H}_{2} \mathrm{O}$ is detected during inspiration, the ventilator (switches) to Pressure Support with a resulting increase in inspiratory flow." This indicates dual targeting as described above (see Table 2). Noting that the breath may switch to pressure support alerts us that the breath sequence is not what it first seemed to be. A breath may be 
patient-triggered with a patient inspiratory effort, and if the effort is large enough and long enough, inspiration is flow-cycled, not time-cycled. Flow cycling (at a certain percent of peak inspiratory pressure) is, as we described above, a form of patient cycling because the time constant of the patient's respiratory system determines when the cycle threshold is met for passive inhalation (hence, inspiratory time is determined by the patient). Alternatively, the patient may make an expiratory effort that cycles inspiration off. Either way, a patient-triggered and patientcycled breath is a spontaneous breath. Thus, spontaneous breaths may occur between mandatory breaths, and the breath sequence is actually IMV. Finally, the tag for this mode is VC-IMVd,d. Note that with dual targeting modes, we need to identify which control variable is in effect at the start of inspiration, and in this case, it is volume. In contrast, the mode called pressure $\mathrm{A} / \mathrm{C}$ with machine volume (CareFusion Avea) is also dual targeting but starts out in pressure control and may switch to volume control. This convention is used because if the criterion that causes the switch between control variables is never met during a breath, the original control variable remains in effect throughout the inspiratory time.

Finally, some modes are composed of compound targeting schemes. For example, some ventilators offer tube compensation, a feature that increases inspiratory pressure in proportion to flow to support the resistive load of breathing through an artificial airway. This is a form of servo targeting. On the Dräger Evita XL ventilator, tube compensation can be added to CMV + AutoFlow to obtain a mode classified as PC-CMVar, where ar represents the compound targeting scheme composed of adaptive plus servo (note the absence of a comma between a and $r$ because we are referring only to the primary breaths, and no secondary breaths exist). A mode classified as PC-IMV with set-point control for both primary (mandatory) and secondary (spontaneous) breaths would have the tag PCIMVs,s (note the comma indicating set-point for primary breaths and set-point for secondary breaths). If tube compensation is used for the spontaneous breaths (eg, Covidien PB840 ventilator), the tag would change to PCIMVs,r. If it is added to both mandatory and spontaneous breaths (eg, Dräger Evita XL ventilator), the tag would change to PC-IMVsr,sr. Another example is IntelliVentASV (Hamilton Medical S1 ventilator), which uses optimal targeting to minimize the work rate and intelligent targeting to establish lung-protective limits and adjust PEEP and $\mathrm{F}_{\mathrm{IO}_{2}}$. The tag for this mode is PC-CMVoi,oi.

The utility of this taxonomy becomes evident when comparing modes on different ventilators (eg, for making a purchase decision), as shown in a recent issue of Health Devices. ${ }^{6}$ We have extended this type of comparison to include several common ICU ventilators (Table 3). Table 3 is sorted by manufacturer and model, control variables, breath sequences, and targeting schemes (simple to complex). Table 4 shows the most commonly used modes for the ventilators described in Table 3 , sorted by classification (tag). Table 4 illustrates how modes that are essentially the same or very similar are given very different names. We have constructed a table of all of the modes on 30 different ventilators from 11 different manufacturers (not shown). The table lists 290 unique names of modes representing 45 different classifications (tags). Dealing with this level of complexity is not unlike the challenge facing clinicians when applying clinical diagnostic reasoning. The elements of the mode taxonomy can thus be seen as analogous to the discriminating and defining features of a set of diagnostic hypotheses, ${ }^{16}$ as shown in Figure 8.

\section{Discussion}

\section{The Problem of Growing Complexity}

We mentioned in the introduction how modes of mechanical ventilation have evolved to a high level of complexity. If we agree that the goal is to be able to appropriately use all modes of ventilation (even if we restrict this goal to a single type of ventilator that might be available), then this implies the ability to compare and contrast their advantages and disadvantages. The urgency for dealing with the complexity of mechanical ventilation is ultimately based on the growing concern for patient safety. The ECRI "has repeatedly stressed the need for users to understand the operation and features of ventilators ... The fact that ventilators are such an established technology by no means guarantees that these issues are clearly understood ... We continue to receive reports of hospital staff misusing ventilators because they're unaware of the device's particular operational considerations." 17

To deal with this complexity, researchers are designing even more complex systems that attempt to better serve the 3 goals of mechanical ventilation (ie, safety, comfort, and liberation)..$^{18}$ For example, Tehrani ${ }^{19}$ has recently described a system designed to automatically control the support level in proportional assist ventilation to guarantee delivery of a patient's required ventilation (serving the goal of safety). This system can also be used to control the proportional assist ventilation support level based on the patient's work of breathing (serving the goal of comfort). Blanch et $\mathrm{al}^{20}$ have developed the Better Care system, which reliably detects ineffective respiratory efforts during expiration (ie, inability of a patient to trigger breaths) with accuracy similar to that of expert intensivists and the EAdi signal (serving the comfort goal). According to Kilic and Kilic, ${ }^{21}$ conventional weaning predictors ignore important dimensions of weaning outcome. They describe a fuzzy logic system that provides an approach that can handle multi-attribute decision making as a tool to over- 
Table 3. Classification of Modes on Common ICU Ventilators

\begin{tabular}{|c|c|}
\hline Mode Name & Tag \\
\hline \multicolumn{2}{|l|}{ Covidien PB840 } \\
\hline A/C volume control & VC-CMVs* \\
\hline SIMV volume control with pressure support & VC-IMVs,s \\
\hline SIMV volume control with tube compensation & VC-IMVs,r \\
\hline $\mathrm{A} / \mathrm{C}$ pressure control & PC-CMVs \\
\hline $\mathrm{A} / \mathrm{C}$ volume control plus & PC-CMVa \\
\hline SIMV pressure control with pressure support & PC-IMVs,s \\
\hline SIMV pressure control with tube compensation & PC-IMVs,r \\
\hline Bi-level with pressure support & PC-IMVs,s \\
\hline Bi-level with tube compensation & PC-IMVs,r \\
\hline SIMV volume control plus with pressure support & PC-IMVa,s \\
\hline SIMV volume control plus with tube compensation & PC-IMVa,r \\
\hline Spontaneous pressure support & PC-CSVs \\
\hline Spontaneous tube compensation & PC-CSVr \\
\hline Spontaneous proportional assist & PC-CSVr \\
\hline Spontaneous volume support & PC-CSVa \\
\hline \multicolumn{2}{|l|}{ Dräger Evita XL } \\
\hline CMV & VC-CMVs \\
\hline CMV with pressure-limited ventilation & VC-CMVd \\
\hline SIMV & VC-IMVs,s \\
\hline SIMV with automatic tube compensation & VC-IMVs,sr \\
\hline SIMV with pressure-limited ventilation & VC-IMVd,s \\
\hline SIMV with pressure-limited ventilation and automatic tube compensation & VC-IMVd,sr \\
\hline Mandatory minute volume ventilation & VC-IMVa,s \\
\hline Mandatory minute volume ventilation with automatic tube compensation & VC-IMVa,sr \\
\hline Mandatory minute volume with pressure-limited ventilation & VC-IMVda,s \\
\hline Mandatory minute volume with pressure-limited ventilation and automatic tube compensation & VC-IMVda,sr \\
\hline Pressure control ventilation plus assisted & PC-CMVs \\
\hline CMV with AutoFlow & PC-CMVa \\
\hline CMV with AutoFlow and tube compensation & PC-CMVar \\
\hline Pressure control ventilation plus/pressure support & PC-IMVs,s \\
\hline APRV & PC-IMVs,s \\
\hline Mandatory minute volume with AutoFlow & PC-IMVa,s \\
\hline SIMV with AutoFlow & PC-IMVa,s \\
\hline Mandatory minute volume with AutoFlow and tube compensation & PC-IMVar,sr \\
\hline SIMV with AutoFlow and tube compensation & PC-IMVar,sr \\
\hline Pressure control ventilation plus/pressure support and tube compensation & PC-IMVsr,sr \\
\hline APRV with tube compensation & PC-IMVsr,sr \\
\hline $\mathrm{CPAP} /$ pressure support & PC-CSVs \\
\hline SmartCare & PC-CSVi \\
\hline CPAP/pressure support with tube compensation & PC-CSVsr \\
\hline \multicolumn{2}{|l|}{ Hamilton Medical G5 } \\
\hline Synchronized controlled mandatory ventilation & VC-CMVs \\
\hline SIMV & VC-IMVs,s \\
\hline SIMV with tube-resistance compensation & CV-IMVs,sr \\
\hline Pressure control CMV & PC-CMVs \\
\hline Adaptive pressure ventilation CMV & PC-CMVa \\
\hline Adaptive pressure ventilation CMV with tube-resistance compensation & PC-CMVar \\
\hline Pressure control CMV with tube-resistance compensation & PC-CMVsr \\
\hline Pressure SIMV & PC-IMVs,s \\
\hline NIV-spontaneous timed & PC-IMVs,s \\
\hline Nasal CPAP-pressure support & PC-IMVs,s \\
\hline APRV & PC-IMVs,s \\
\hline DuoPAP & PC-IMVs,s \\
\hline
\end{tabular}


Table 3. Continued

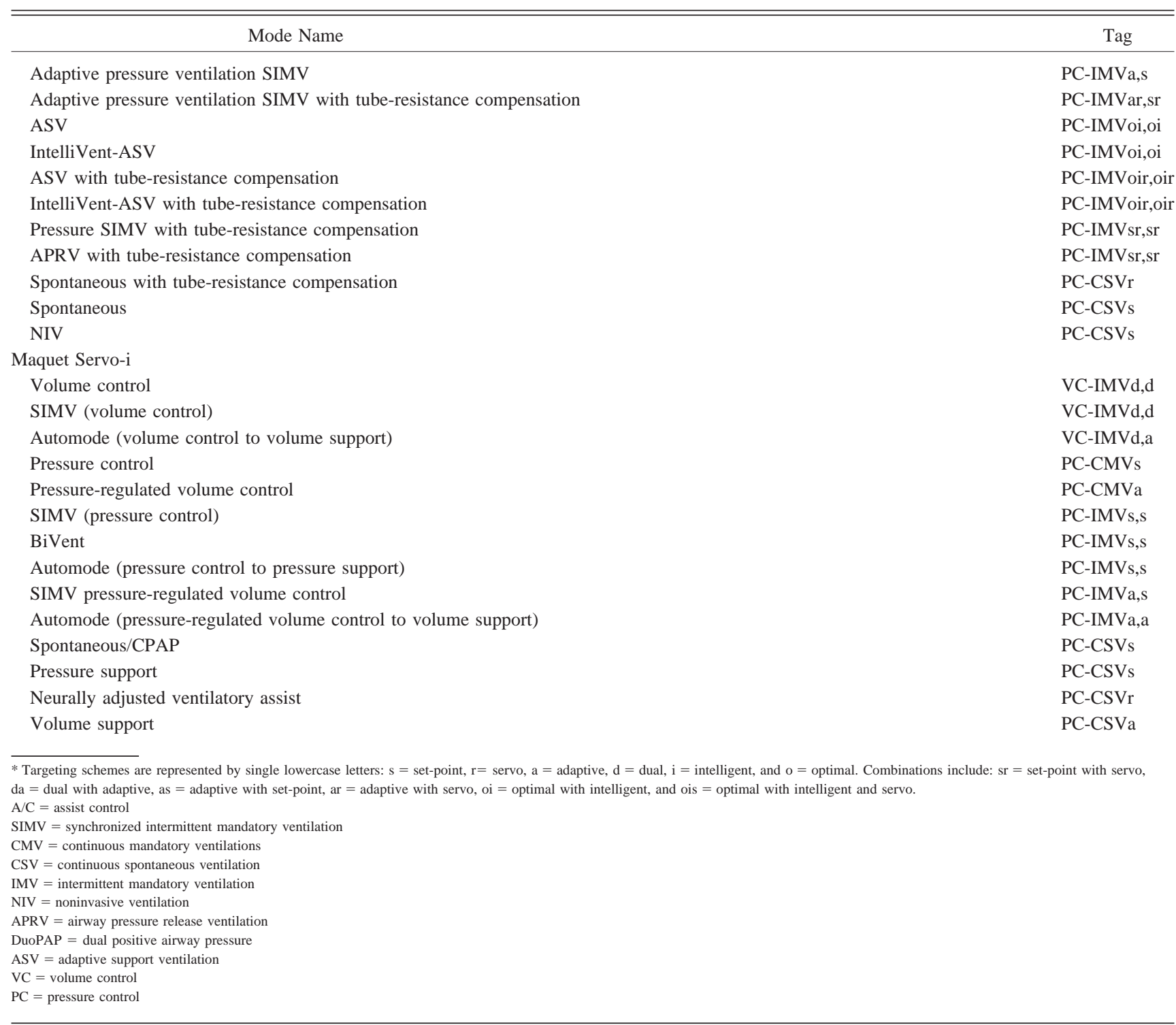

come the weaknesses of currently used weaning predictors (serving the goal of liberation). Wysocki et $\mathrm{al}^{22}$ provide a very good overview of technical and engineering considerations regarding closed-loop controlled ventilation, as well as tangible clinical evidence that such systems make mechanical ventilation safer and more efficient.

\section{The Problem of Identifying Unique Modes}

Before we can compare modes, we must have a list of available modes. To generate such a list, we cannot just copy the names of modes found in ventilator operators' manuals for 2 reasons. First, there is no consistency among manufacturers regarding how modes are named: some names are the same but the modes are different, and some names are different but the modes are the same. Second, complex ICU ventilators offer features that, when activated, result in modes that are not named by the manufacturer and, in many cases, not even recognized as different modes. Such ambiguity makes learning about how ventilators work very difficult.

Thus, before we can generate a list of modes to compare, we first have to find some way to deal with this confusion. One way is to distinguish between a mode name, which is determined by the manufacturer, and a mode tag or general classification. However, before we can do that, we must have a practical taxonomy. And before a taxonomy can be constructed, there must be a standardized glossary (or controlled vocabulary, as it is called by taxonomists) of relevant terms. ${ }^{15,23}$ The need for a standardized 
Table 4. Most Common Modes in Table 3 Sorted by Tag to Show Which Mode Names Have Equivalent Mode Classifications

\begin{tabular}{|c|c|c|c|c|}
\hline Tag & Covidien PB840 & Dräger Evita XL & Hamilton G5 & Maquet Servo-i \\
\hline VC-CMVs* & $\mathrm{A} / \mathrm{C}$ volume control & CMV & $\begin{array}{l}\text { Synchronized controlled } \\
\text { mandatory ventilation }\end{array}$ & $\mathrm{NA} \dagger$ \\
\hline VC-IMVs,s & $\begin{array}{l}\text { SIMV volume control with } \\
\text { pressure support }\end{array}$ & SIMV & SIMV & NA $\ddagger$ \\
\hline PC-CMVs & $\mathrm{A} / \mathrm{C}$ pressure control & $\begin{array}{l}\text { Pressure control ventilation } \\
\text { plus assisted }\end{array}$ & Pressure control CMV & Pressure control \\
\hline PC-CMVa & $\mathrm{A} / \mathrm{C}$ volume control plus & CMV with AutoFlow & $\begin{array}{l}\text { Adaptive pressure ventilation } \\
\text { CMV }\end{array}$ & $\begin{array}{l}\text { Pressure-regulated volume } \\
\text { control }\end{array}$ \\
\hline \multirow[t]{5}{*}{ PC-IMVs,s } & $\begin{array}{l}\text { SIMV-pressure control with } \\
\text { pressure support }\end{array}$ & $\begin{array}{l}\text { Pressure control ventilation } \\
\text { plus/pressure support }\end{array}$ & Pressure SIMV & SIMV (pressure control) \\
\hline & \multirow{4}{*}{$\begin{array}{l}\text { Bi-level with pressure } \\
\text { support }\end{array}$} & \multirow[t]{4}{*}{ APRV } & NIV-spontaneous timed & BiVent \\
\hline & & & Nasal CPAP-pressure support & $\begin{array}{l}\text { Automode (pressure control to } \\
\text { pressure support) }\end{array}$ \\
\hline & & & APRV & \\
\hline & & & DuoPAP & \\
\hline PC-IMVa,s & $\begin{array}{l}\text { SIMV volume control plus } \\
\text { with pressure support }\end{array}$ & $\begin{array}{l}\text { Mandatory minute volume } \\
\text { with AutoFlow } \\
\text { SIMV with AutoFlow }\end{array}$ & $\begin{array}{l}\text { Adaptive pressure ventilation } \\
\text { SIMV }\end{array}$ & $\begin{array}{l}\text { SIMV pressure-regulated } \\
\text { volume control }\end{array}$ \\
\hline PC-CSVs & Spontaneous pressure support & $\mathrm{CPAP} /$ pressure support & Spontaneous & Spontaneous/CPAP \\
\hline PC-CSVa & Spontaneous volume support & NA & NA & Volume support \\
\hline \multicolumn{5}{|c|}{$\begin{array}{l}\text { * Targeting schemes are represented by single lowercase letters: } \mathrm{s}=\text { set-point, and } \mathrm{a}=\text { adaptive. } \\
\dagger \text { Volume control continuous mandatory ventilation (VC-CMV) is not available because the mode called volume control allows some breaths to be patient-triggered and patient-cycled; hence, they } \\
\text { are spontaneous, making the breath sequence intermittent mandatory ventilation (IMV) rather than CMV. } \\
\text { † VC-IMV is available only with dual targeting, called SIMV (volume control) with the tag VC-IMVd,d. } \\
\text { PC = pressure control } \\
\text { CSV = continuous spontaneous ventilation } \\
\text { A/C = assist control } \\
\text { SIMV = synchronized intermittent mandatory ventilation } \\
\text { NA = not available } \\
\text { APRV = airway pressure release ventilation } \\
\text { DuoPAP = dual positive airway pressure } \\
\text { NIV = noninvasive ventilation }\end{array}$} \\
\hline
\end{tabular}

vocabulary is the reason we included one in the supplementary materials (http://www.rcjournal.com). This vocabulary has been carefully developed by the authors over the last 20 years with the specific purpose of establishing basic concepts that are logically consistent across all applications.

\section{The Problem of Teaching Mechanical Ventilation}

We believe that there is a growing and under-recognized problem regarding training in the art and science of mechanical ventilation that frequently leads to operational errors. The reason is that technology is expanding faster than our educational resources. Not even a 4-year respiratory care program can afford the time to ensure the abovementioned mechanical ventilation competencies for RRTs. The challenge for physicians may be even greater because they generally rely on their residency (rather than medical school) to learn mechanical ventilation. But according to at least one study, “. . . internal medicine residents are not gaining important evidence-based knowledge needed to provide effective care for patients who require mechanical ventilation." 24

So how do instruction programs deal with the challenge? We recently conducted an informal survey of members of the AARC specialty section on education. We asked program directors to send us their outlines for teaching mechanical ventilation. On the basis of what we found, we contend there are 3 categories of organizational structure: (1) simple lists of skills needed to operate specific ventilators, (2) lists of topics ranging from indications for ventilation to weaning (and everything in between) with no apparent order, and (3) topic organization identical to or closely following the table of contents in textbooks on mechanical ventilation. Having written ventilator-related content in such textbooks, we can safely say that such material was never designed to be used as the basis for a class syllabus. In most of our previous writings focusing on modes of mechanical ventilation, ${ }^{7,14,25,26}$ the emphasis has been on descriptions of modes rather than the background technical knowledge required to understand them. That knowledge was assumed on the part of the reader 


\section{TAXONOMY For Mechanical Ventilation}

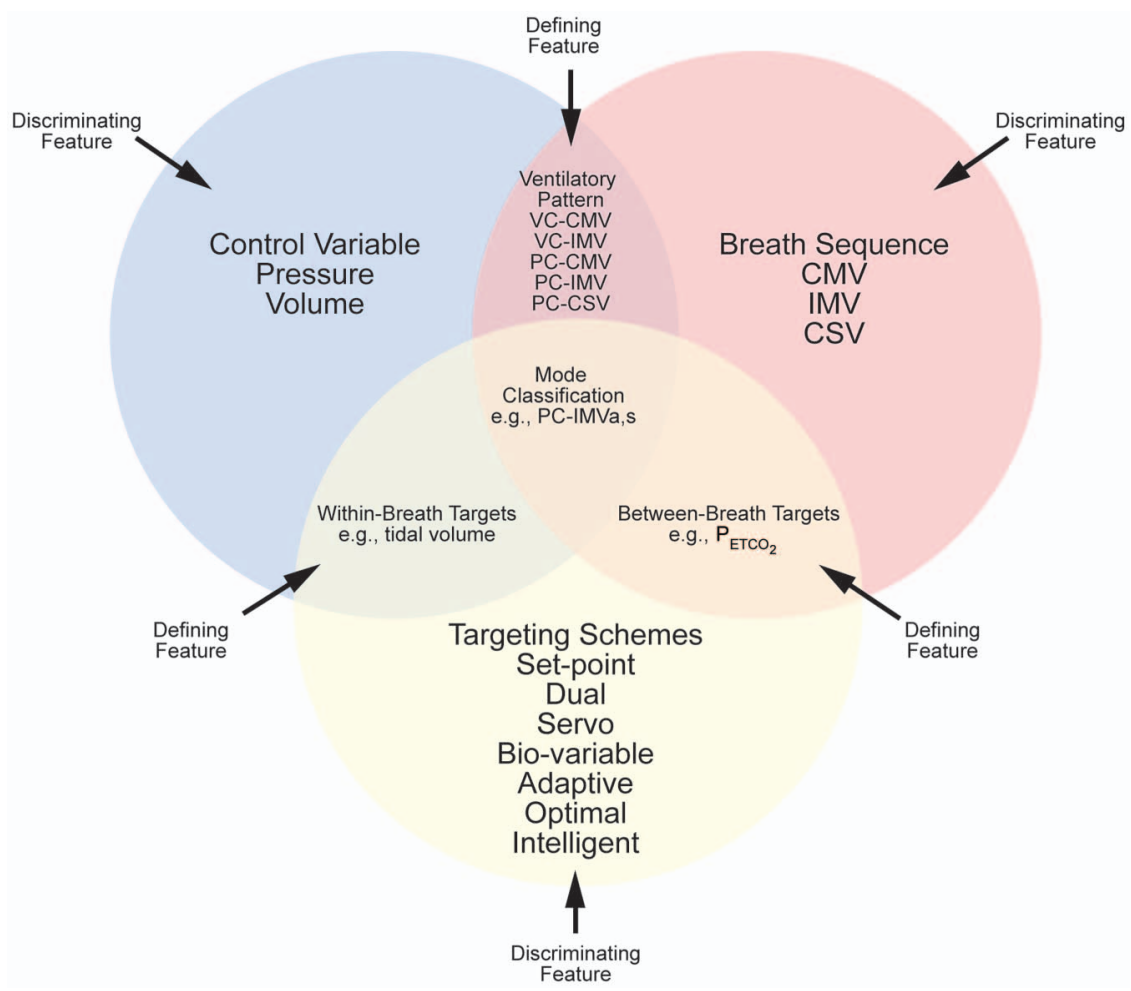

Fig. 8. Venn diagram illustrating how the mode taxonomy can be viewed in terms of discriminating features and defining features. $\mathrm{VC}=$ volume control; $\mathrm{PC}=$ pressure control; $\mathrm{CMV}=$ continuous mandatory ventilation; IMV = intermittent mandatory ventilation; $\mathrm{CSV}=$ continuous spontaneous ventilation; $\mathrm{P}_{\mathrm{ETCO}}$ = end-tidal partial pressure of carbon dioxide; a = adaptive targeting; $\mathrm{s}=$ set-point targeting. Courtesy Mandu Press.

(and instructor). This seems to be a universal theme among authors of both articles and book chapters on how ventilators work, but as the technology grows more complex, the gap between assumed and actual knowledge becomes wider. We trust that this article helps to narrow that gap.

\section{The Problem of Implementation}

The first problem regarding implementation of any taxonomy (and its underlying standardized vocabulary) is, of course, reaching a tipping point in acceptance by stakeholders. We believe that such acceptance is achievable only if the tools for implementing the taxonomy are simple, practical, and efficient in permitting both the identification and comparison of modes. The acceptance of this taxonomy by the ECRI is a step in the right direction. We hope that the detailed definitions, descriptions, and algorithms provided here will address the deficiencies in the available textbook references. Indeed, such tools are amenable to dissemination using mobile computing technology such as tablet computers and smartphones.

The second problem is ongoing maintenance of the taxonomy. Terms and concepts necessarily change as technology evolves. Ideally, a professional organization should take responsibility for this function. The International Or- ganization for Standardization and the Integrating the Healthcare Enterprise Rosetta Terminology Mapping project are working toward such a goal. Alternatively, the AARC might be an appropriate venue for maintaining the taxonomy as they do for clinical practice guidelines.

\section{Conclusions}

The rapid increase in the number and complexity of mechanical ventilators, and specifically the modes they offer, has outpaced development of tools for describing them. A key problem has been the lack of a practical classification system or taxonomy. Partial solutions to that problem have been offered in our previous publications. In this paper, we developed a full taxonomy and standardized vocabulary for modes of mechanical ventilation. We showed how the taxonomy is based on 10 fundamental constructs, or maxims, describing ventilator technology. Finally, we showed how to use the taxonomy to classify modes of ventilation found on common ICU ventilators. Identifying and classifying modes are necessary steps before being able to compare their relative merits and ultimately to choose the most appropriate mode to serve the goals of care for a particular patient. ${ }^{18}$ The tools offered in this paper (including the standardized vocabulary and 


\section{TaXonomy for Mechanical Ventilation}

2 summary handouts in the supplementary materials at http://www.rcjournal.com) serve as a means for achieving the mechanical ventilation competencies of the respiratory therapist in 2015 and beyond. ${ }^{4}$ Indeed, they serve the needs of all stakeholders, including clinicians (to understand treatment options), researchers (to evaluate treatment options), educators (to prepare the next generation of ventilator experts), administrators (to make purchase decisions), and, perhaps most important of all, manufacturers (to explain the technical capabilities of their products and serve the needs of the other stakeholders).

\section{REFERENCES}

1. Kacmarek RM, Durbin CG Jr, Barnes TA, Kageler WV, Walton JR, O'Neil EH. Creating a vision for respiratory care in 2015 and beyond. Respir Care 2009;54(3):375-389.

2. Barnes TA, Gale DD, Kacmarek RM, Kageler WV. Competencies needed by graduate respiratory therapists in 2015 and beyond. Respir Care 2010;55(5):601-616.

3. Barnes TA, Kacmarek RM, Kageler WV, Morris MJ, Durbin CG Jr. Transitioning the respiratory therapy workforce for 2015 and beyond. Respir Care 2011;56(5):681-690.

4. Kacmarek RM. Mechanical ventilation competencies of the respiratory therapist in 2015 and beyond. Respir Care 2013;58(6):10871096.

5. Cairo JM, Pilbeam SP. Mosby's respiratory care equipment, 8th edition. St. Louis, MO: Mosby/Elsevier; 2009.

6. ECRI. Take a breath: our review of three portable ventilators. Health Devices 2013;42(8):248-261.

7. Chatburn RL, Volsko TA, Hazy J, Harris LN, Sanders S. Determining the basis for a taxonomy of mechanical ventilation. Respir Care 2012;57(4):514-524.

8. Overbaugh RC, Schultz L. Bloom's taxonomy. http://ww2.odu.edu/ educ/roverbau/Bloom/blooms_taxonomy.htm. Accessed August 17, 2013.

9. Coutinho Myrrha MA, Vieira DS, Moraes KS, Lage SM, Parreira VF, Britto RR. Chest wall volumes during inspiratory loaded breathing in COPD patients. Respir Physiol Neurobiol 2013;188(1):15-20.

10. Marini JJ, Crooke PS 3rd, Truwit JD. Determinants and limits of pressure-preset ventilation: a mathematical model of pressure control. J Appl Physiol 1989;67(3):1081-1092.
11. Sinderby C, Beck JC. Neurally adjusted ventilatory assist. In: Tobin MJ, editor. Principles and practice of mechanical ventilation, 3rd edition. New York: McGraw-Hill, 2013;351-375.

12. Kondili E, Alexopoulou C, Xirouchaki N, Vaporidi K, Georgopoulos D. Estimation of inspiratory muscle pressure in critically ill patients. Intensive Care Med 2010;36(4):648-655.

13. Babic MD, Chatburn RL, Stoller JK. Laboratory evaluation of the Vortran Automatic Resuscitator Model RTM. Respir Care 2007; 52(12):1718-1727.

14. Chatburn RL, Mireles-Cabodevila E. Closed-loop control of mechanical ventilation: description and classification of targeting schemes. Respir Care 2011;56(1):85-102.

15. Rabec C, Langevin B, Rodenstein D, Perrin C, Leger P, Pepin JL, Janssens JP, Gonzalez-Bermejo J, SomnoNIV Group. Chatburn RL. Ventilatory Modes. What's in a name? Respir Care 2012;57(12): 2138-2139; author reply 2139-2150.

16. Bowen JL. Educational strategies to promote clinical diagnostic reasoning. N Engl J Med 2006;355(21):2217-2225.

17. ECRI. Health Devices 2002;31(7).

18. Mireles-Cabodevila E, Hatipoğlu U, Chatburn RL. A rational framework for selecting modes of ventilation. Respir Care 2013;58(2): 348-366.

19. Tehrani FT. A control system for mechanical ventilation of passive and active subjects. Comput Methods Programs Biomed 2013;110(3): 511-518.

20. Blanch L, Sales B, Montanya J, Lucangelo U, Garcia-Esquirol O, Villagra A, et al. Validation of the Better Care system to detect ineffective efforts during expiration in mechanically ventilated patients: a pilot study. Intensive Care Med 2012;38(5):772-780.

21. Kilic YA, Kilic I. A novel fuzzy logic inference system for decision support in weaning from mechanical ventilation. J Med Syst 2010; 34(6):1089-1095.

22. Wysocki M, Jouvet P, Jaber S. Closed loop mechanical ventilation. J Clin Monit Comput 2014;28(1):49-56.

23. Hedden, $\mathrm{H}$. The accidental taxonomist. Medford, NJ: Information Today; 2010.

24. Cox CE, Carson SS, Ely EW, Govert JA, Garrett JM, Brower RG, et al. Effectiveness of medical resident education in mechanical ventilation. Am J Respir Crit Care Med 2003;167(1):32-38.

25. Chatburn RL. Classification of ventilator modes: update and proposal for implementation. Respir Care 2007;52(3):301-323.

26. Chatburn RL. Understanding mechanical ventilators. Expert Rev Respir Med 2010;4(6):809-819. 